z.B. mit einer unzureichenden Vernetzung des Kollagens im Knochen erklärt werden. Dieses Defizit sei allerdings mit den üblichen Verfahren zur Knochendichtemessung (DXA) nicht feststellbar. Er wünscht sich daher neue Diagnoseverfahren im Hinblick auf Osteoporose bei Typ-2-Diabetikern, etwa neue 3DScanverfahren in der Routinemessung oder die Bestimmung von Biomarkern. Zudem müsste das Prinzip der Osteoporosetherapie vor allem bei älteren Typ-2-Diabetikern überdacht werden, da die klassischen antiresorptiven Wirkstoffe den ohnehin verringerten Knochenstoffwechsel der Diabetespatienten weiter absenken.

\section{Risikopotenzial von Antidiabetika}

Auf das unterschiedliche Risikopotenzial von Antidiabetika für Frakturen wies einmal mehr Dr. Matteo Monami von der Universität Florenz hin. Glitazone wirken dabei sowohl über eine Steigerung der Knochenresorption als auch eine verringerte Knochenneubildung negativ auf die Knochendichte und -festigkeit. Dabei sieht er die weni- ger starken Auswirkungen bei Männern z.B. darin begründet, dass Testosteron die Differenzierung von mesenchymalen Stammzellen in Adipozyten statt Osteoblasten hemmt.

Bei einer Therapie mit Insulin ist ebenfalls ein erhöhtes Frakturrisiko belegt, auch nach Adjustierung etwa für Hypoglykämien mit konsekutivem Sturz, sagte Monami. Neutral im Hinblick auf Frakturen seien dagegen Metformin und Insulinsekretagoga. Günstig bezüglich des Knochenstoffwechsels könnten sich die inkretinbasierten Therapien erweisen, da auch GLP-1 die Differenzierung von mesenchymalen Stammzellen in Adipozyten statt Osteoblasten verringert. Dies muss aber erst weiter untersucht werden.

\section{Knochenhormon als Antidiabetikum?}

Nicht nur ein Diabetes kann Auswirkungen auf den Knochen haben, auch umgekehrt wird ein Schuh draus. So entdeckte ein Forscherteam um Dr. Patricia Ducy von der Columbia Universität in New York einen Regelkreis zwi- schen Knochen- und Glukosestoffwechsel. Eine zentrale Bedeutung hat dabei das von Osteoblasten produzierte und von Osteoklasten aktivierte Hormon Osteocalcin. Es erhöht die Insulinsekretion und -sensitivität sowie die Betazellproliferation im Pankreas und senkt die Fettmasse über Adiponektinbildung in den Fettzellen. Sein Gegenspieler, genannt Esp, bewirkt das Gegenteil. Der Kreis schließt sich, indem Insulin wiederum die Osteocalcinproduktion und -aktivierung fördert. Dabei ist besonders interessant, dass erst die Knochenresorption durch Osteoklasten das Osteocalcin $\mathrm{pH}$-abhängig aktiviert. Dies legt den Schluss nahe, das eine antiresorptive Medikation bei Osteoporose Insulinresistenz erzeugen könnte, was allerdings sehr selten geschehe, so Ducy. Der Regelkreis sei jedoch ein Ansatz für zukünftige Therapien bei Diabetes.

SARAH LOUISE PAMPEL

- Quellen: Symposium „Diabetes and bone“, EASD-Kongress, Stockholm, 20.-24.9.2010; [1] Janghorbani et al. Am J Eidemiol 2007;166: 495-505; [2]Vestergaard P et al. Calcif Tissue Int 2009;84(1):45-55

\title{
Schon bei Gesunden ist das Glukosegleichgewicht fragil
}

- Eine kurzzeitige Belastung mit hochkalorischer Ernährung, wenig Bewegung und Prednisolon setzt selbst bei Gesunden schon nach etwa zwei Wochen fatale Stoffwechselprozesse in Gang. Dies ergab eine kleine Untersuchung mit zehn jungen Probanden ohne Risikofaktoren für Diabetes. Bei den Probanden, allesamt Kaukasier, wurde mit einer etwa zehntägigen hochkalorischen Diät, physikalischer Inaktivität und 37,5 mg Prednisolon pro Tag eine Insulinresistenz ausgelöst. Anschließend maß man Glukoseparameter und die Inkretinhormone GIP und GLP-1 nach einer flüssigen 520-kcal-Mahlzeit. Es stellte sich heraus, dass sich bereits ohne dass das Gewicht der jungen Männer beeinflusst worden war - so- wohl die Nüchternglukose als auch die Insulinantwort erhöht hatten. Die verringerte Insulinsensitivität hatte keinen Einfluss auf die postprandiale GLP-1-Steigerung. Allerdings war das Inkretinhormon GIP (glucosedependent insulinotropic polypeptide) postprandial nun deutlich erhöht, ebenso wie die Glukagonsekretion. Für GIP wird postuliert, dass es die Verbindung zwischen fettreicher Ernährung, Adipositas, Insulinresistenz und Typ-2-Diabetes herstellt. Außerdem erhöht es die Glukagonausschüttung.

Die Forscher schließen aus ihren Ergebnissen, dass die erhöhte GIPAusschüttung keine Ursache sondern eine Folge der Insulinresistenz ist, ebenso wie die Hyperglukagonämie,

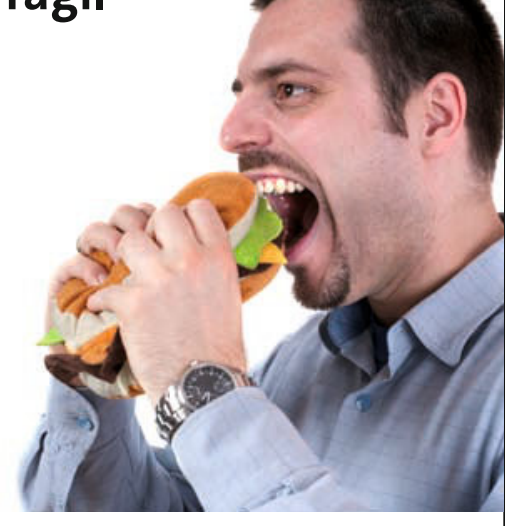

die auch bei adipösen Typ-2-Diabetikern zu beobachten ist. Die erniedrigte GLP-1-Antwort dagegen scheint nicht von einer Insulinresistenz getriggert zu werden.

SPA =

- Knop FK et al. Diabetologia 2010;53 (Suppl 1) S26o. Poster 647 